OECDpublishing

YOUTH ASPIRATIONS ANDTHE REALITY OF JOBS IN AFRICA

OECD DEVELOPMENT POLICY PAPERS

March 2021 No. 38 

OECD Development Policy Papers

March 2021 - No. 38

\section{Youth aspirations and the reality of jobs in Africa}

By Adrien Lorenceau, Ji-Yeun Rim and Toma Savitki

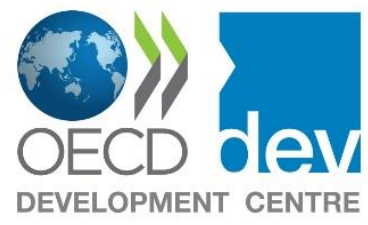


This work is published under the responsibility of the Secretary-General of the OECD. The opinions expressed and arguments employed herein do not necessarily reflect those of the OECD, its Development Centre or of their member countries.

This document, and any map included herein, are without prejudice to the status of or sovereignty over any territory, to the delimitation of international frontiers and boundaries and to the name of any territory, city or area.

This document was authorised for publication by Mario Pezzini, Director of the Development Centre and Special Advisor to the OECD Secretary-General on Development.

Keywords: youth employment, skills mismatch, youth career aspirations

JEL classification: J11, J13, J18, J23

(C) OECD 2021 


\section{Abstract}

The gap between youth aspirations and the reality of the labour markets in Africa is large. Career aspirations of young Africans have little in common with current and projected labour demand in the region, making it unlikely that they will go through a smooth school-to-work transition. Evidence from ten African countries shows that what youth in these countries value most is job security, such as work in the public sector. Agriculture related work or medium-skilled jobs in manufacturing are the least attractive for young Africans. Policies can help address the misalignment between youth employment preferences and employment opportunities. A two-pronged approach is recommended: i) helping young people shape career aspirations that are realistic and that can fit with the world they will be entering, and ii) improving the quality of jobs with due regard to the job conditions that matter for young people. 


\section{Table of contents}

Abstract 3

Introduction $\quad 5$

Aspirations of young Africans $\quad 5$

African youth job satisfaction $\quad 7$

African youth aspiration gaps $\quad 9$

$\begin{array}{ll}\text { Employment status } & 10\end{array}$

Skills mismatch 16

Policy recommendations $\quad 18$

$\begin{array}{ll}\text { References } & 21\end{array}$

\section{Figures}

Figure 1. A large share of students would like to work in the public sector 6

Figure 2. Desired occupation categories, 15-29-year-old students $\quad 7$

Figure 3. Share of satisfied young workers, using a raw and adjusted measure 8

Figure 4. Satisfied young workers wish to change jobs for various reasons 8

Figure 5. Difference between the distribution of aspirations and the distribution of workers at different skills levels of the occupations by country

Figure 6. African youth aspirations in terms of sector of activity

Figure 7. Distribution of young workers by employment status 11

Figure 8. Distribution of self-employed youth workers according to their reason for being self-employed 11

Figure 9. Distribution of unpaid family workers according to the reason for joining this status 12

Figure 10. Distribution of young workers by qualification level of occupation 13

Figure 11. Distribution of young workers by type of industry 14

Figure 12. Likelihood of keeping the same job over the next 12 months, among all workers 15

Figure 13. The share of young wage employees with contracts of unlimited duration $\quad 15$

Figure 14. Informality among young workers in developing countries 16

Figure 15. Young workers' own perceptions about the relevance of their education to their current job

requirements

Figure 16. Qualification according to a normative mismatch measure based on the level of education required for each type of occupation 


\section{Introduction}

Today, one in six is a young person aged between 15 and 24 . The global youth population is expected to reach 1.3 billion by 2030 and to continue to increase until 2065, mostly led by Africa. In sub-Saharan Africa (SSA) some 375 million youth are expected to join the labour force by 2030 (ILO, 2016[1]). Policy makers across the world, and particularly in Africa, are preoccupied with the great challenge of helping millions of young people find decent work, as conveyed in Goal 8 of the 2030 Agenda for Sustainable Development. The challenge is particularly daunting in developing countries where informal labour markets and weak enforcement of labour standards keep many young people in low-quality jobs and poverty.

Good jobs matter for development and deliberate efforts are needed to improve the quality of jobs and make work pay. However, little is known about what actually matters for young people in terms of job characteristics and employment conditions. A survey ${ }^{1}$ across 32 developing and emerging economies provides new insights on youth career aspirations. This paper hones in on ten African countries as a compendium to the report Youth Aspirations and the Reality of Jobs in Developing Countries: Mind the Gap (OECD, 2017[2]). It is produced as part of the EU-OECD Youth Inclusion project. It places youth employment preferences at the forefront of the analysis and asks: What is the nature of youth career aspirations and job-related drivers of job satisfaction? What shapes such employment preferences? How likely is it that young people will be able to meet their job aspirations? What can policy makers do to reduce the gap between youth preferences and the reality of jobs?

\section{Aspirations of young Africans}

In Africa, the majority of students aspire to work in the public sector. The share of students wishing to work in the public sector, including international organisations and non-governmental organisations (NGOs), ranges from $60 \%$ in the Republic of the Congo (Congo) to $78 \%$ in Zambia (Figure 1). This result confirms that public employment remains highly valued by young Africans, most likely because it combines characteristics valued by young workers such as job stability and security. These preferences are likely to influence the way young African men and women make decisions about subjects to study.

\footnotetext{
1 The study involved harmonisation and analysis of data from school-to-work transition surveys collected between 2012 and 2015 in 32 developing and transition countries in Africa, Asia, Europe and Latin America and the Caribbean. Insights on youth career aspirations are derived from information gathered from students aged 15 to 29 about the sector of activity and the type of jobs they would like to hold later in life.
} 
Figure 1. A large share of students would like to work in the public sector

Percentage

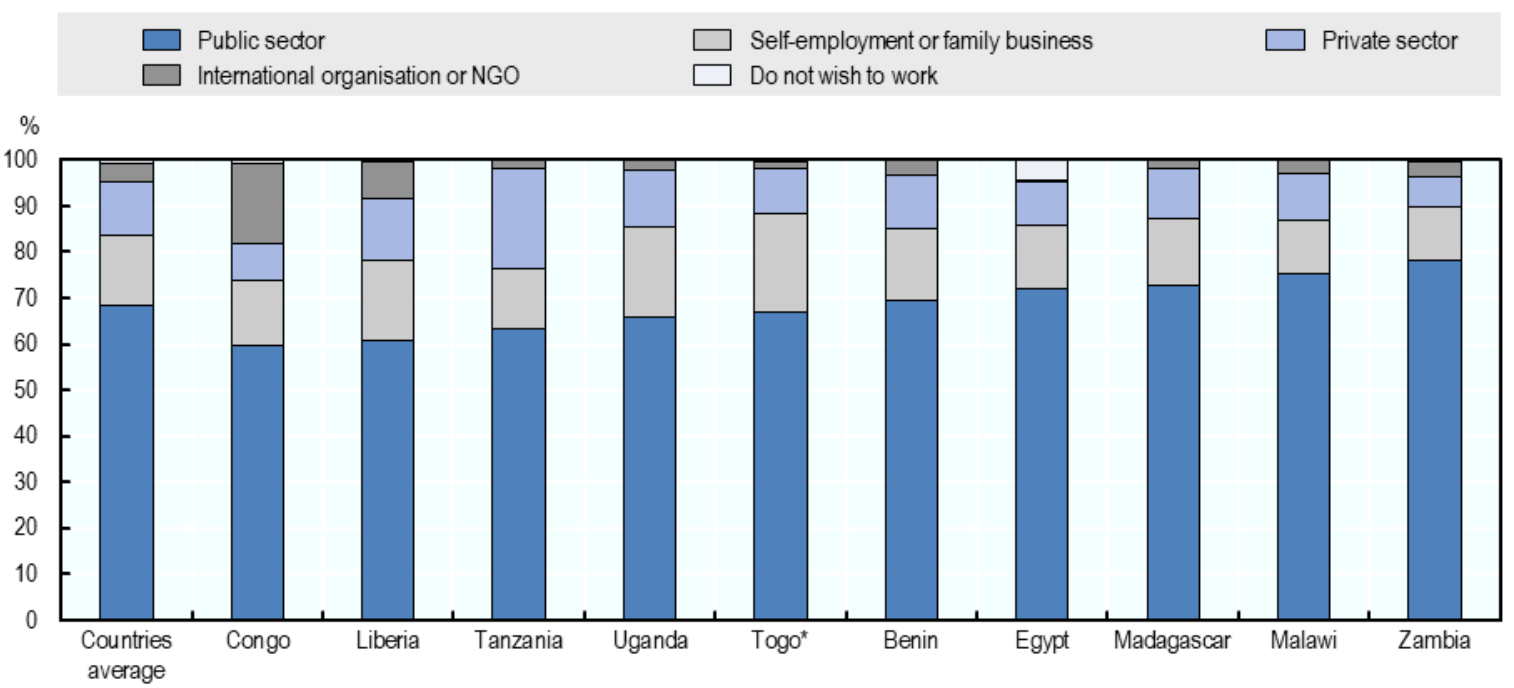

Note: The figure represents the distribution of answers from students who were asked: "Ideally, who would you like to work for?". * Estimations for Togo do not account for sampling weights as they are missing in the data.

Source: Own calculations based on ILO School-to-Work Transition Surveys 2012-15.

Most surveyed African students aspire for high-skilled occupations. Using the International Standard Classification of Occupations (ISCO) definitions, when students are asked which type of job they would like to do, the vast majority declared that they would like to be in a high-skilled occupation such as manager (ISCO 1), professional (ISCO 2) or technician or associated professional (ISCO 3). Figure 2 shows that, on average across the ten African countries, more than $80 \%$ of students aspire to work in a high-skilled profession, of whom $62 \%$ as a professional, $5 \%$ as a senior official or manager and $15 \%$ as a technician or associated professional. All these professions require at least some level of tertiary education according to the ISCO categories (ILO, 2012[3]). What is remarkable is that students' occupational preferences were highly similar across countries. Liberia is the only country among the ten African countries where less than half of students wish to work in top-skilled occupations (legislators, senior officials, managers and professionals).

Few students express the wish to work in intermediate-skilled occupations such as clerical support, services, sales or crafts. On average, only one in seven students surveyed chose services, trade or craft as their preferred future occupation. Jobs in the service sector hold greatest appeal for Liberian students $(8 \%)$, while crafts and related occupations are most attractive to students in Uganda (11\%). The data further show that fewer than $2 \%$ of students aspire to become skilled agricultural workers, while only $1 \%$ aspire to become plant operators or assembly line workers in the industrial sector, even though such activities are often considered to be an important engine for growth in developing countries (Figure 2). 
Figure 2. Desired occupation categories, 15-29-year-old students

Percentage

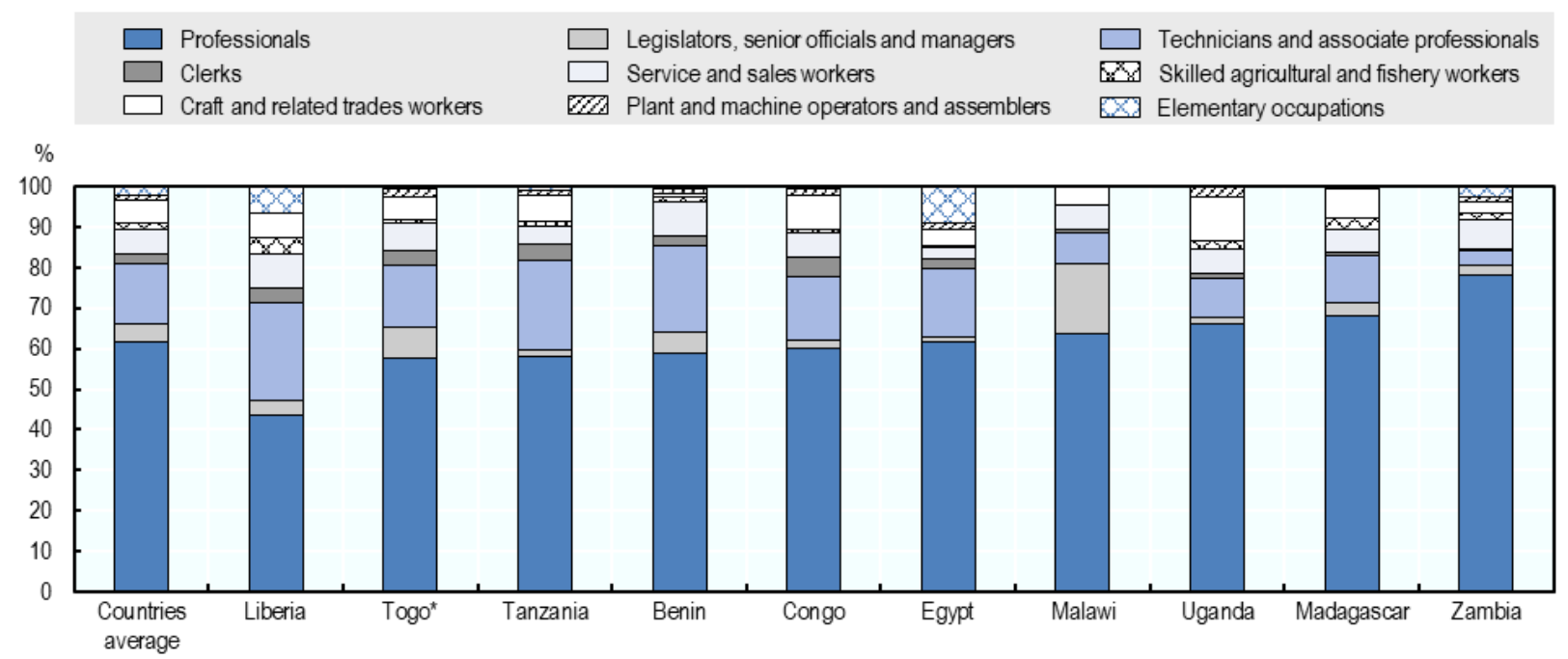

Note: The figure represents the distribution of answers from students who were asked: "Ideally, what type of work would you like to do?" Occupation categories correspond to the nine major groups under the International Statistical Classification of Occupation (ISCO-08).

* Estimations for Togo do not account for sampling weights as they are missing in the data.

Source: Own calculations based on ILO School-to-Work Transition Surveys 2012-15.

\section{African youth job satisfaction}

The majority of young Africans would like to change their current jobs. On average, across the ten African countries, $67 \%$ of young workers answer that they are satisfied with their present jobs. However, when a more restrictive definition of satisfaction is used (corrected by the desire to not change the current job), only $35 \%$ say that they are satisfied with their current job and do not wish to change employment (Figure 3 ). In other words, when probed if they would change jobs if they could, the majority answered yes. It is worth noting that there is widespread heterogeneity across countries on the effect of using an adjusted measure of job satisfaction. In countries such as Zambia or Tanzania, using a more restrictive measure decreases the share of truly satisfied individuals by more than half. 
Figure 3. Share of satisfied young workers, using a raw and adjusted measure

Percentage

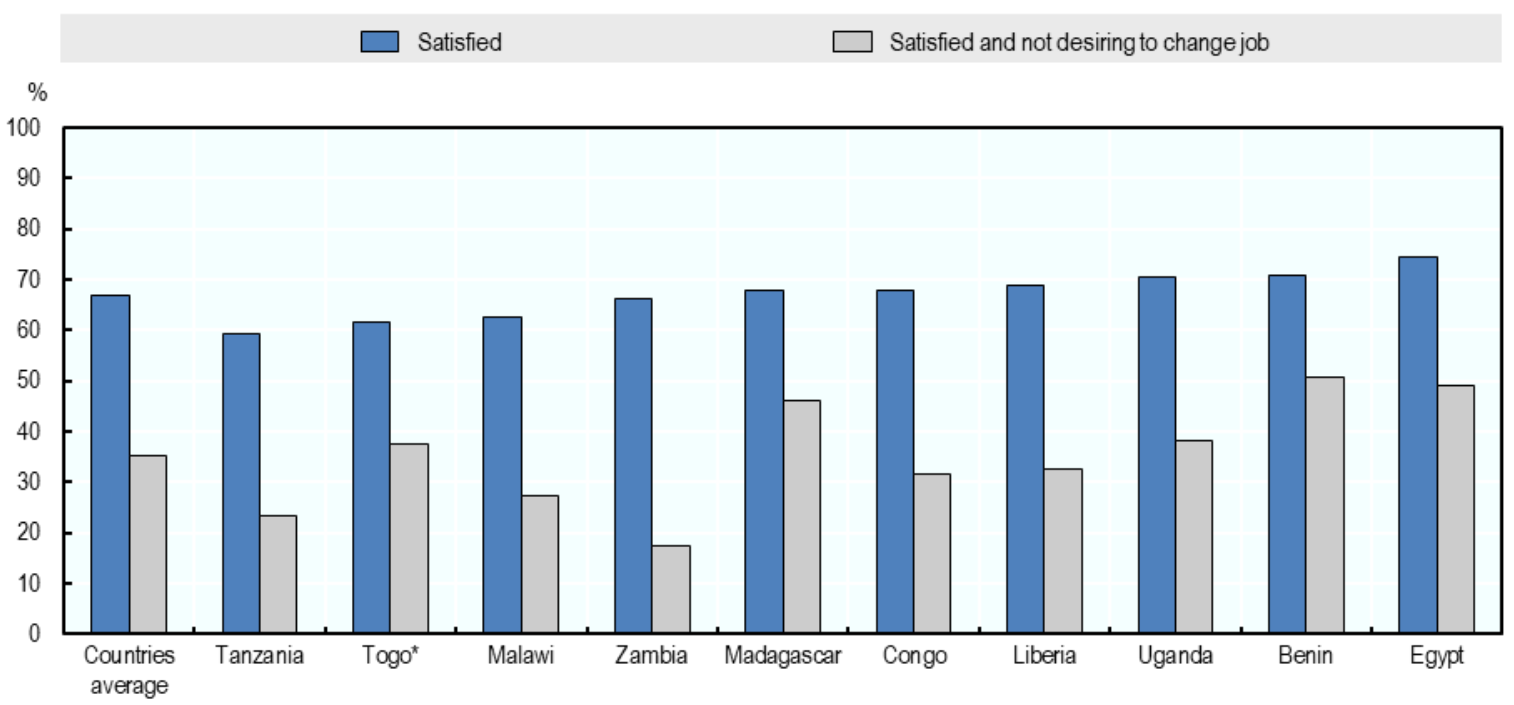

Note: * Estimations for Togo do not account for sampling weights as they are missing in the data.

Source: Own calculations based on ILO School-to-Work Transition Surveys 2012-15.

The reason most cited to change jobs is to get higher pay. The majority of young African workers who are satisfied with their jobs, but would change if they could, cited higher pay as the main reason (Figure 4). The higher the job satisfaction the less likely are individuals wishing to change jobs or actively looking for a job. This shows that, overall, young workers are consistent in judging their employment situations.

\section{Figure 4. Satisfied young workers wish to change jobs for various reasons}

\section{Percentage}

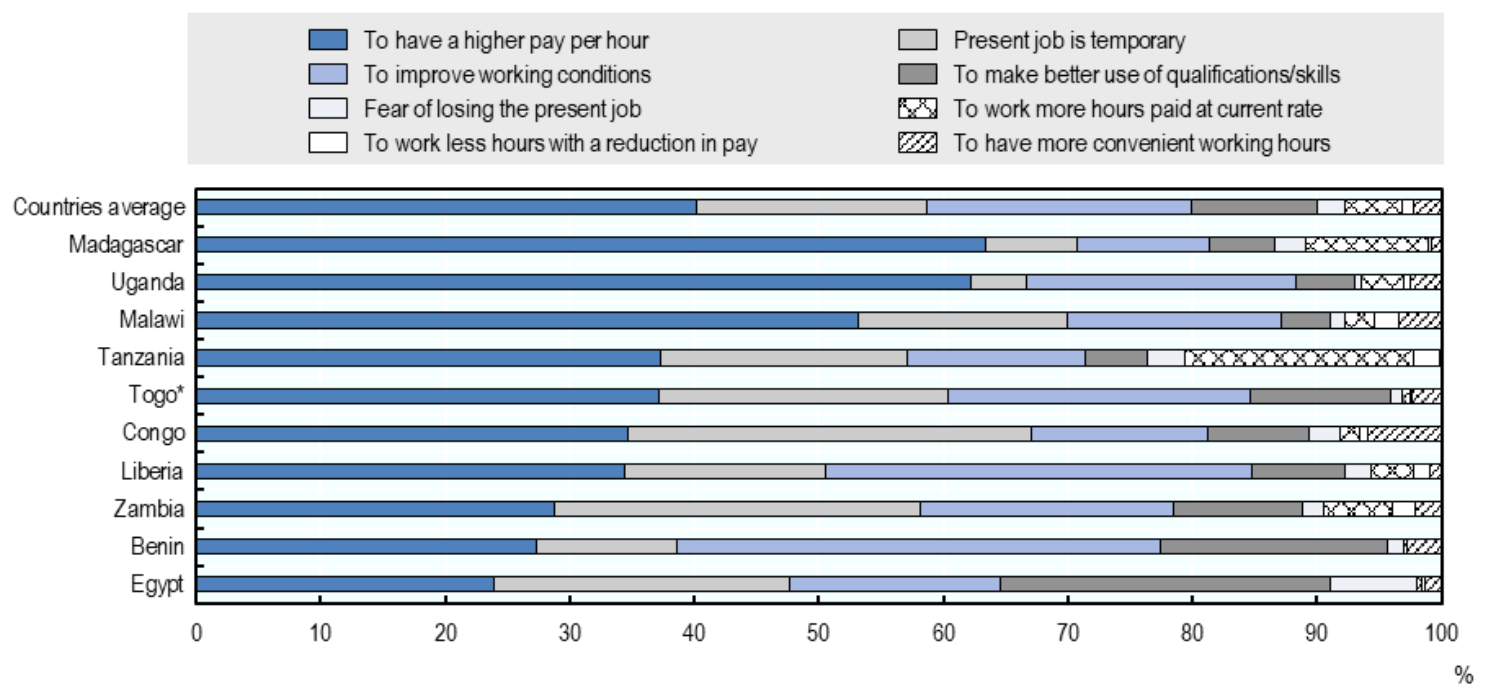

Note: * Estimations for Togo do not account for sampling weights as they are missing in the data.

Source: Own calculations based on ILO School-to-Work Transition Surveys 2012-15. 


\section{African youth aspiration gaps}

Unrealistic career aspirations are challenging in Africa. On average, in the ten African countries surveyed, the difference between the share of students who said they wanted to work in high-skilled occupations and the actual share of highly skilled young workers in the labour market at the time of the survey is $73 \%$ (Figure 5).

Figure 5. Difference between the distribution of aspirations and the distribution of workers at different skills levels of the occupations by country

Percentage

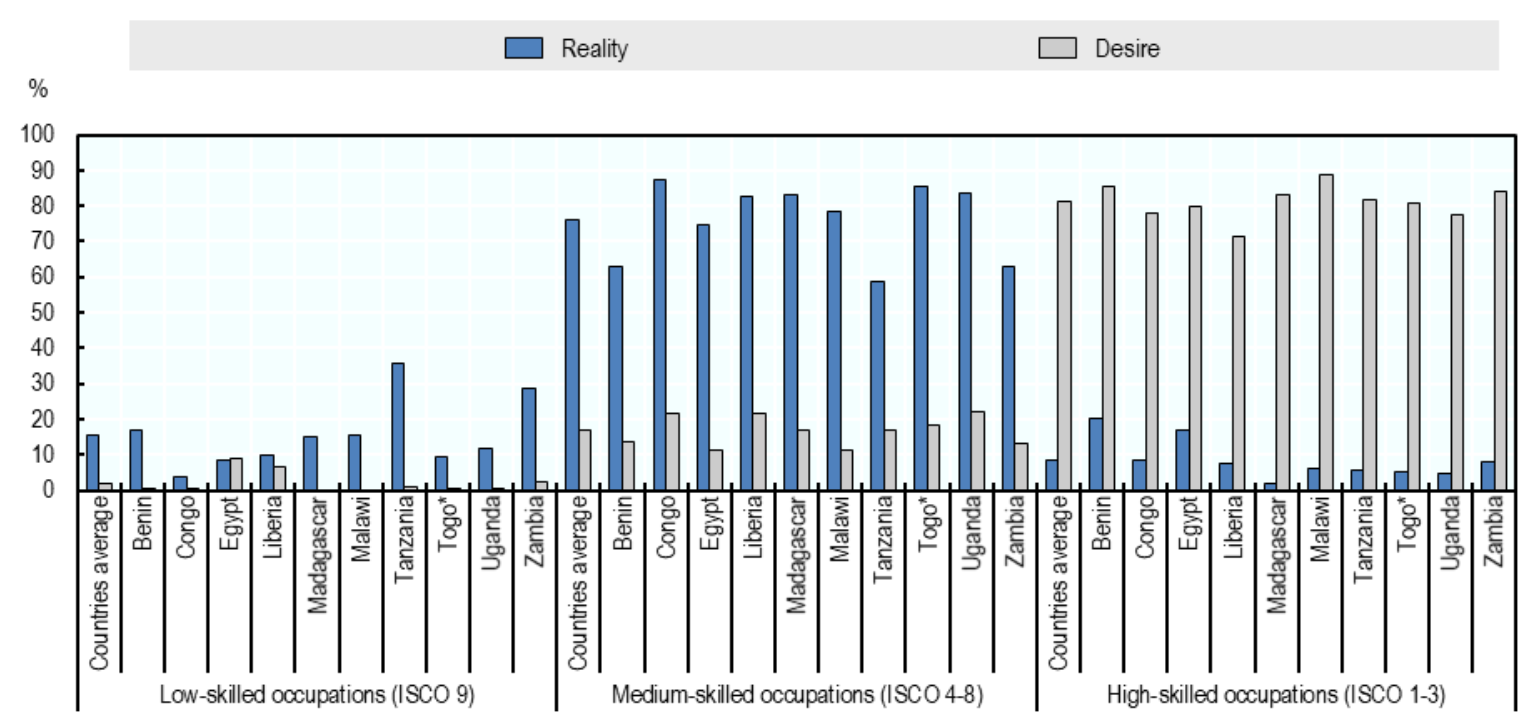

Note: Data are missing for Tunisia. * Estimations for Togo do not account for sampling weights as they are missing in the data. Source: Own calculations based on ILO School-to-Work Transition Surveys 2012-15.

The demand for public-sector jobs exceeds by far the actual employment opportunities in this sector. While around $74 \%$ of students desire to work for the public sector, on average across the ten countries, the public sector accounts for a maximum of just $12 \%$ of employment among young workers (including workers in state-owned enterprises). This leaves about $62 \%$ of young people with unfulfilled aspirations (Figure 6 ). In contrast, the private sector accounts, on average, for $55 \%$ of youth employment while only $10 \%$ of young students said they wanted to work in this sector. These gaps are likely to affect education choices and translate into phenomena such as job queuing in the public sector, which is largely observed in developing and emerging countries. In this respect, extending youth access to social protection in the non-state sector and encouraging formal labour relations could reinforce the attractiveness of the private sector. 
Figure 6. African youth aspirations in terms of sector of activity

Percentage

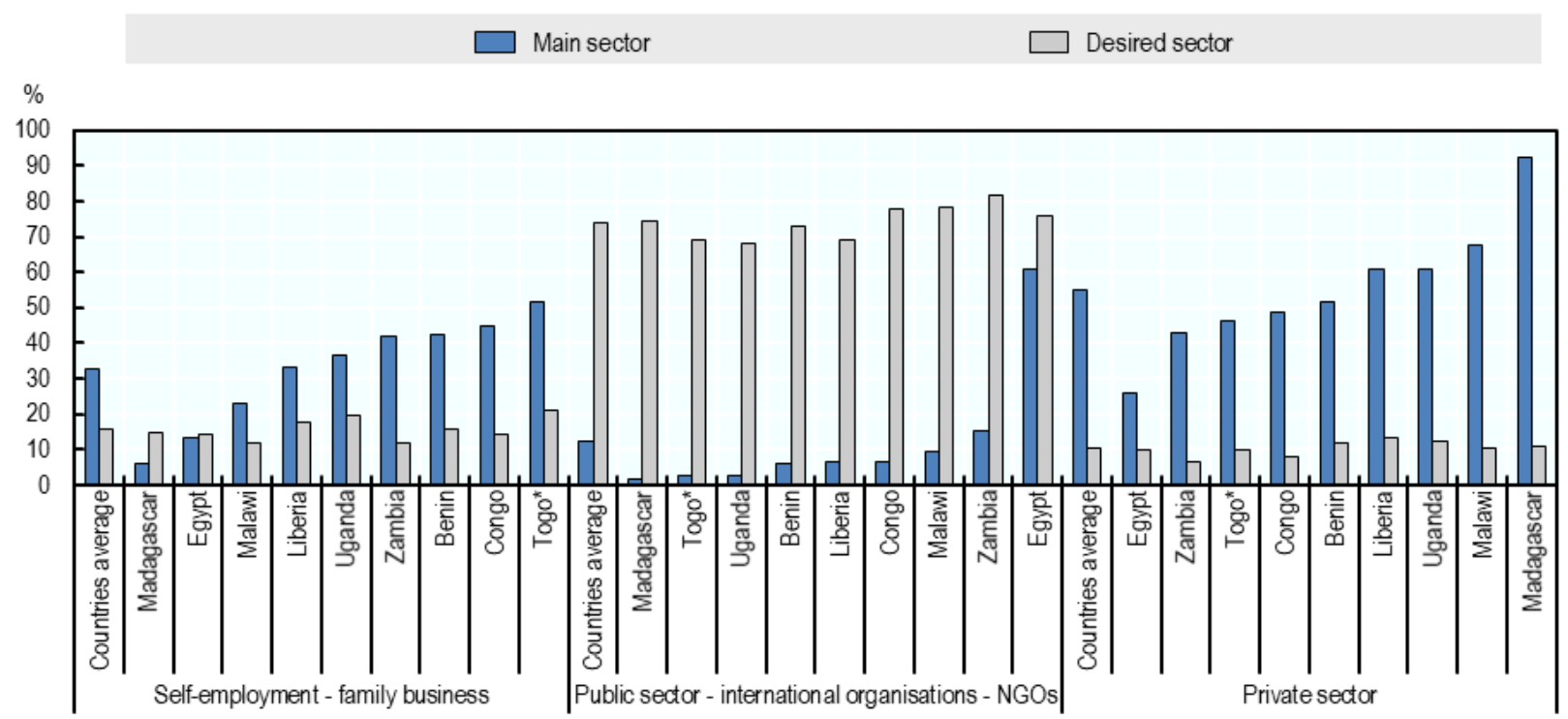

Note: Wage employment in the public sector includes employment in international organisations, NGOs and public companies. Data are missing for Tanzania and Tunisia. ${ }^{*}$ Estimations for Togo do not account for sampling weights as they are missing in the data.

Source: Own calculations based on ILO School-to-Work Transition Surveys 2012-15.

\section{Employment status}

Employment status is a source of job satisfaction. Self-employment is a common form of employment among African youth and accounts for $40 \%$ of youth employment on average for the ten countries, ranging from $30 \%$ in Zambia to $60 \%$ in Malawi. On average, wage jobs account for $28 \%$ of youth employment status. (Figure 7). Engaging in unpaid family work is not an unusual form of employment in developing countries. Contributing family workers, often referred to as unpaid family workers, engage in a specific and common form of employment in many African countries. They are not inactive - they are actually working in the family business or activity, but do not receive an explicit payment (either in kind or cash) for their work. Usually they receive food and lodging in exchange for their contribution. On average across the ten countries, about $27 \%$ of all young workers are contributing family workers (Figure 7 ). The share of young workers in unpaid family work ranges from $8 \%$ in the Republic of the Congo to $55 \%$ in Madagascar. 
Figure 7. Distribution of young workers by employment status

Percentage

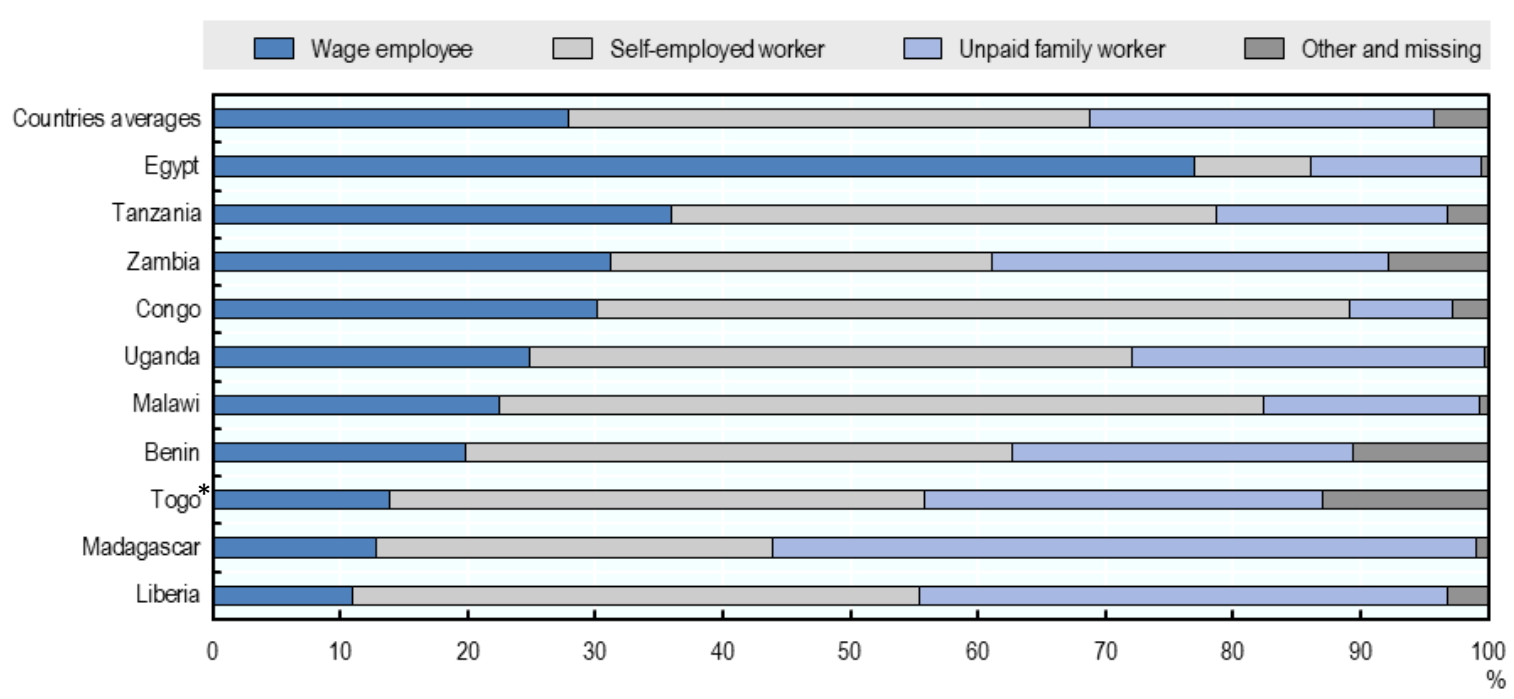

Note: Data are missing for Tunisia. * Estimations for Togo do not account for sampling weights as they are missing in the data. Source: Own calculations based on ILO School-to-Work Transition Surveys 2012-15.

Whether by choice or for family reasons, self-employment is often a choice by default due to lack of better paid jobs. On average across the ten African countries, $46 \%$ of young self-employed workers joined selfemployment by default, either because they could not find wage employment or were forced by the family (Figure 8). The share of young workers who chose self-employment to get more independence or higher pay is $34 \%$ and $13 \%$, respectively.

Figure 8. Distribution of self-employed youth workers according to their reason for being self-employed

Percentage

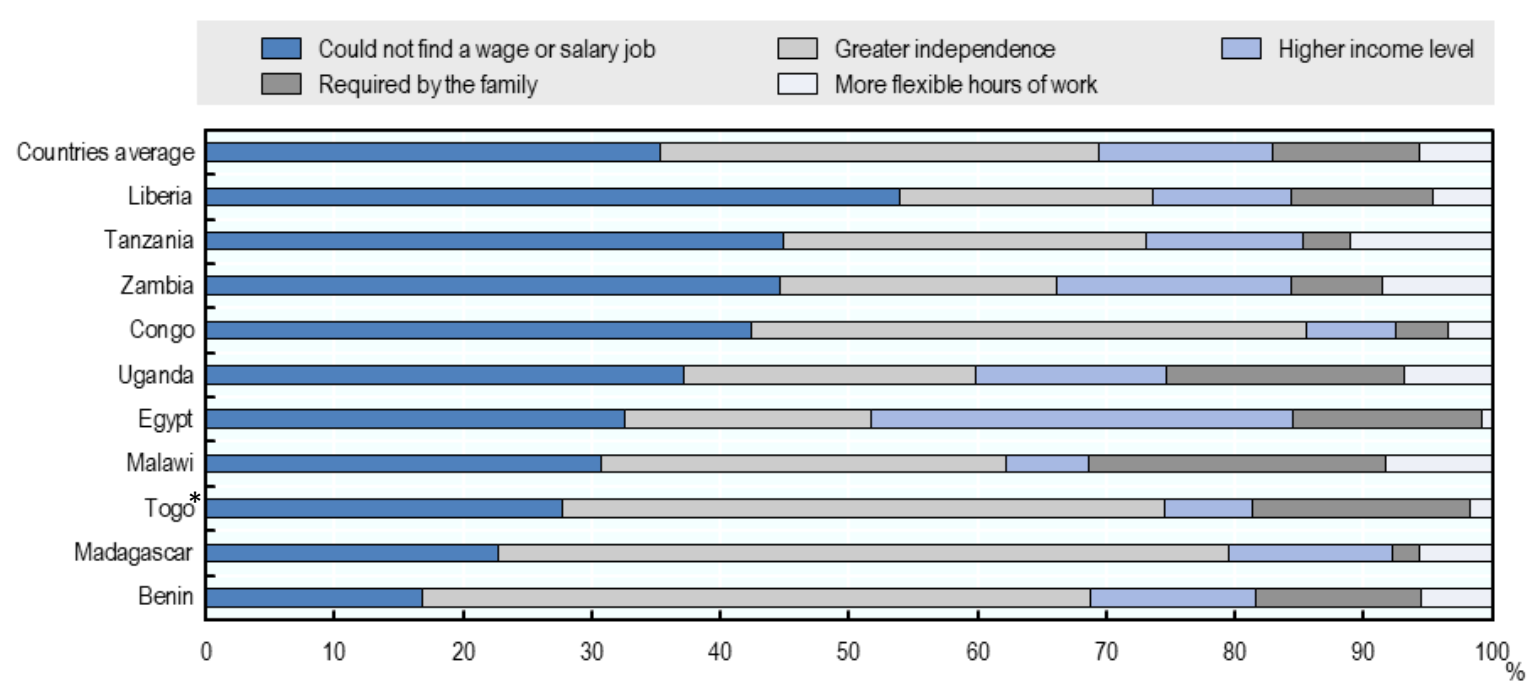

Note: Data are missing for Tunisia. ${ }^{*}$ Estimations for Togo do not account for sampling weights as they are missing in the data. Source: Own calculations based on ILO School-to-Work Transition Surveys 2012-15. 
An examination of the reasons why young people engage in unpaid family work indicates that few voluntarily chose this status, while family influence plays a central role. On average across the ten African countries, young people engage in unpaid family work mostly because it is required by the family (64\%), and also as a way to learn the family business (12\%). When unpaid family work is not a choice by default, it can be associated with a higher level of satisfaction than wage employment (Figure 9).

\section{Figure 9. Distribution of unpaid family workers according to the reason for joining this status}

\section{Percentage}

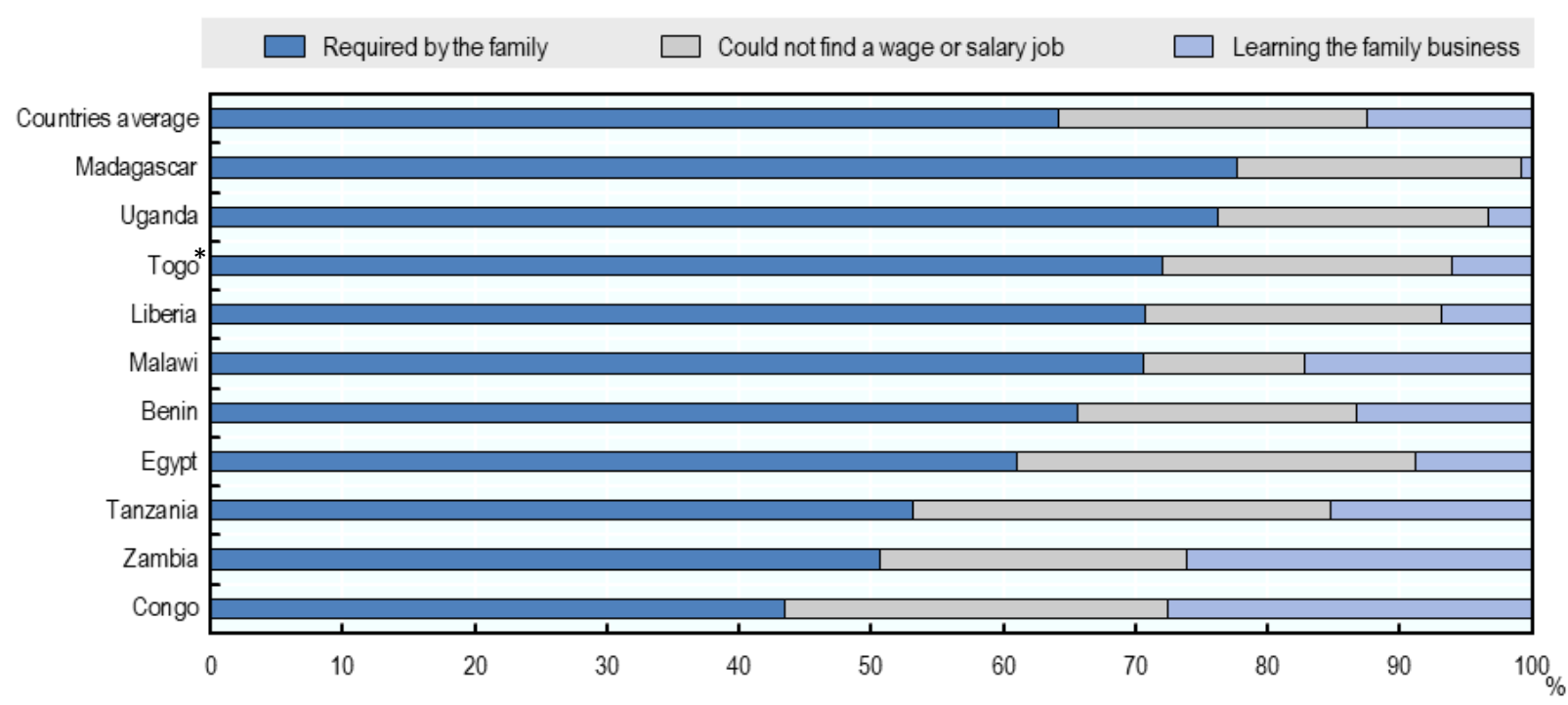

Note: * Estimations for Togo do not account for sampling weights as they are missing in the data.

Source: Own calculations based on ILO School-to-Work Transition Surveys 2012-15.

Having a high-skilled job brings about greater job satisfaction. However in African countries, few young people are able to hold such jobs. The distribution of workers across occupations presented in Figure 10 reflects both the overall structure of the economies and the types of occupations that are more accessible to young people. On average across the ten African countries, only $8 \%$ of young workers are engaged in high-skilled occupations, compared to about $76 \%$ in medium-skilled occupations and $16 \%$ in low-skilled occupations. In Africa only a small share of working young people are engaged in high-skilled occupations (from $2 \%$ in Madagascar to $20 \%$ in Benin). Those in low-skilled jobs range from $4 \%$ in Congo to $36 \%$ in Tanzania. 
Figure 10. Distribution of young workers by qualification level of occupation

Percentage

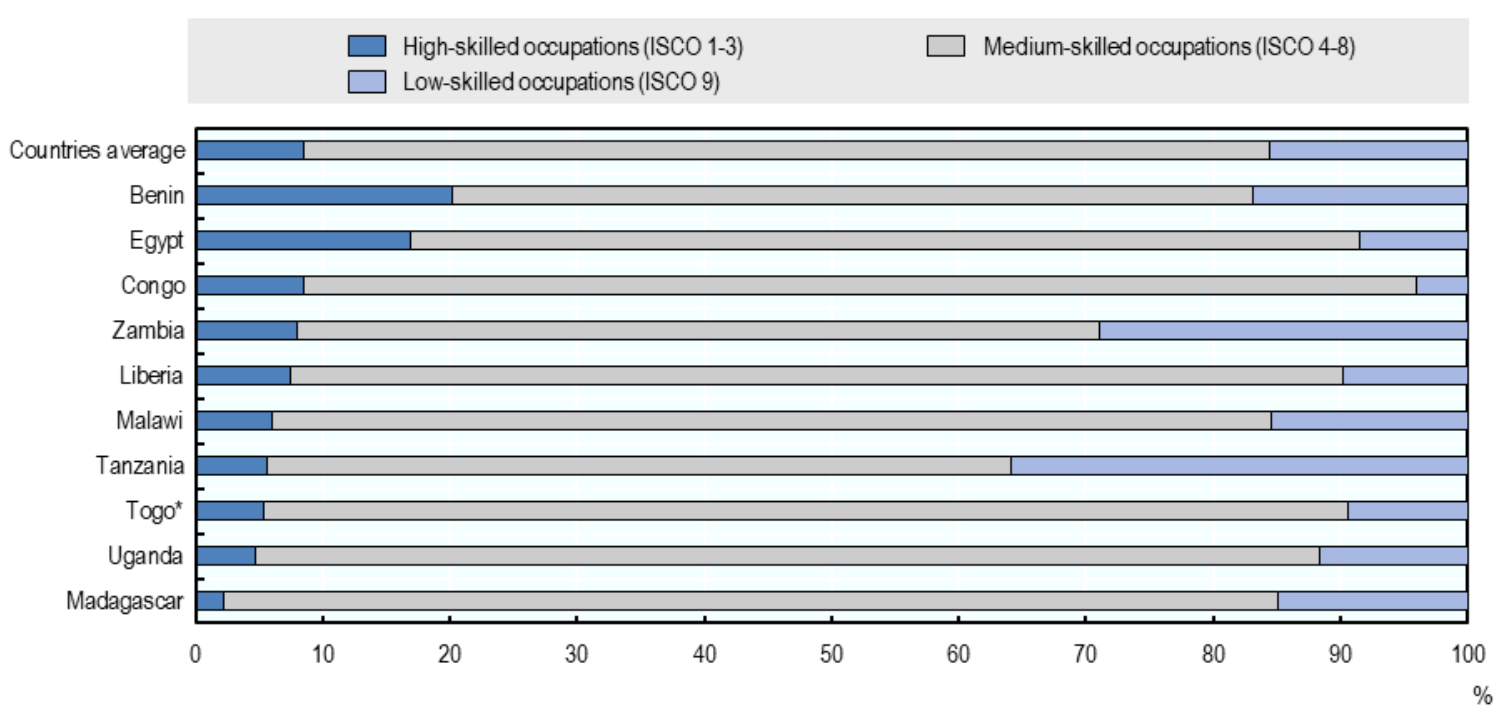

Note: Data are missing for Tunisia. * Estimations for Togo do not account for sampling weights as they are missing in the data. Source: Own calculations based on ILO School-to-Work Transition Surveys 2012-15.

Agriculture remains an important source of jobs for many young people in Africa, even though it does not produce high job satisfaction. Around 39\% of African youth are working in agriculture, $14 \%$ in manufacturing and construction, $26 \%$ in trade and transportation, and $21 \%$ in all other services (Figure 11). Young workers in agriculture are less often satisfied with their work than those in other occupations. Yet agriculture remains an important source of jobs for many young people in several countries in the developing world (AfDB et al., 2012[4]). This indicates the importance of investing in agriculture, improving access to markets, developing the use of information and communication technology, and supporting innovations in the sector in order to reconcile young people with agriculture and attract talented young people to agriculture-related occupations. 
Figure 11. Distribution of young workers by type of industry

Percentage

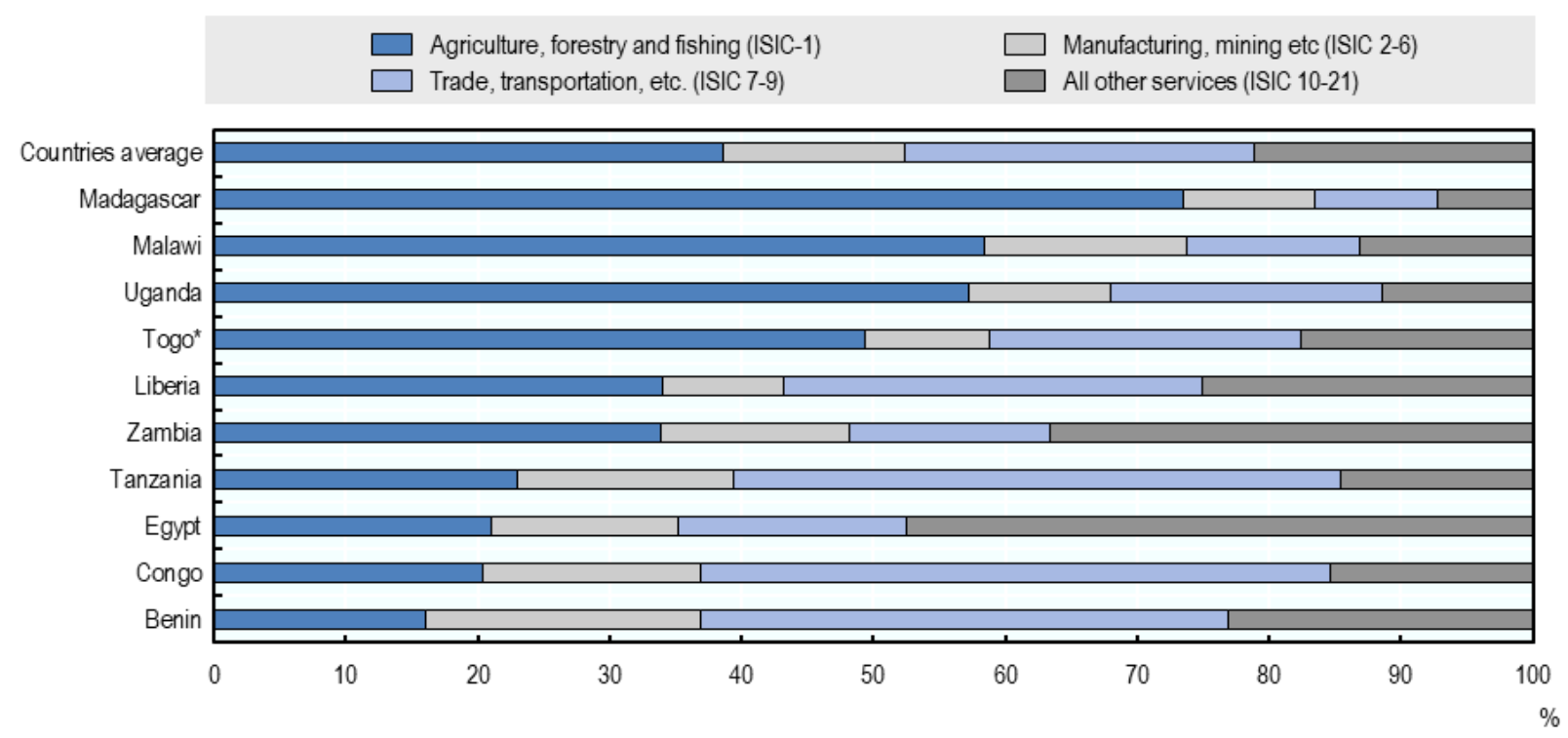

Note: Based on the International Standard Industry Classification (ISIC), industries are aggregated in four categories: agriculture, forestry and fishing (ISIC 1); manufacturing, mining, electricity and water supply related activities and construction (ISIC 2-6); wholesale and retail trade, repair, transportation and storage, accommodation and food services activities (ISCI 7-9); and other services activities including information, communication, finance, real estate, administrative services, education, etc. (ISIC 10 to 21). * Estimations for Togo do not account for sampling weights as they are missing in the data.

Source: Own calculations based on ILO School-to-Work Transition Surveys 2012-15.

A low level of job security drives job satisfaction down and affects a non-negligible share of young workers. Two indicators can be used to assess the level of job security among the youth workforce in developing countries. The first indicator is subjective and relates to the worker's own feeling that s/he can keep the current employment over the next 12 months. The second indicator is objective, but restricted to wage employees only, and refers to the employee's type of contract (unlimited versus limited). On average across the ten African countries, $60 \%$ of young workers report that they are likely to keep their current employment situation, about $25 \%$ are not certain and $15 \%$ think they are unlikely to stay in their current job (Figure 12), but with wide variations between countries (e.g. $6 \%$ of young workers in Uganda do not think they will keep their jobs while it is $31 \%$ in Zambia). 
Figure 12. Likelihood of keeping the same job over the next 12 months, among all workers

Percentage

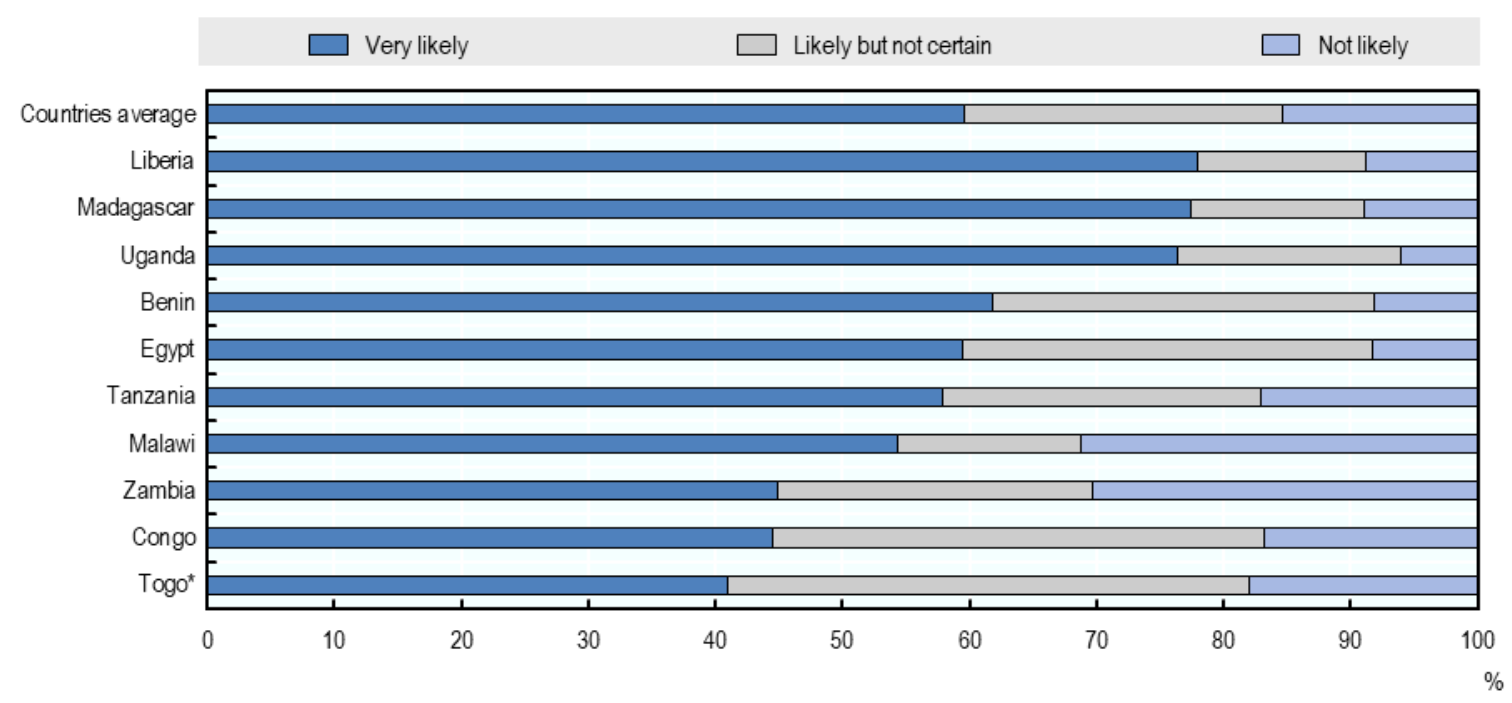

Note: * Estimations for Togo do not account for sampling weights as they are missing in the data. Data for Tunisia are missing.

Source: Own calculations based on ILO School-to-Work Transition Surveys 2012-15.

Regarding the second indicator, the data show that, on average, $57 \%$ of young wage employees benefit from an unlimited work contract (Figure 13). But this average hides important disparities across countries. Only $40 \%$ of youth wage employees in Egypt have contracts with unlimited duration, compared to more than $73 \%$ in Congo. Addressing job security concerns thus appears to be one of the most important directions toward better job satisfaction.

\section{Figure 13. The share of young wage employees with contracts of unlimited duration}

\section{Percentage}

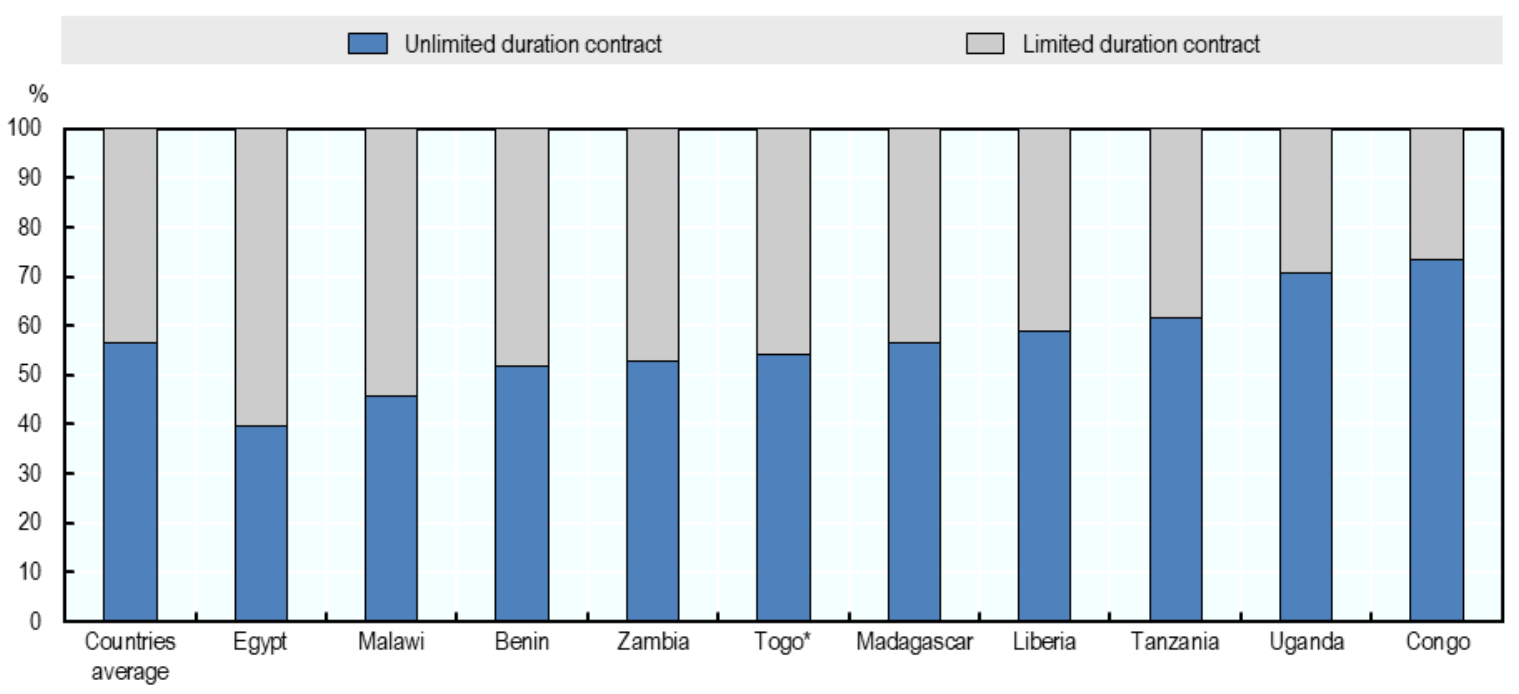

Note: * Estimations for Togo do not account for sampling weights as they are missing in the data.

Source: Own calculations based on ILO School-to-Work Transition Surveys 2012-15. 
While more formal labour relations raise job satisfaction, a large number of young Africans work in the informal economy. On average across countries, only $18 \%$ of young workers are engaged in a registered activity (Figure 14). While the share of young workers engaged in a registered activity is above $41 \%$ in Tanzania, it declines to $7 \%$ in Madagascar.

\section{Figure 14. Informality among young workers in developing countries}

\section{Percentage}

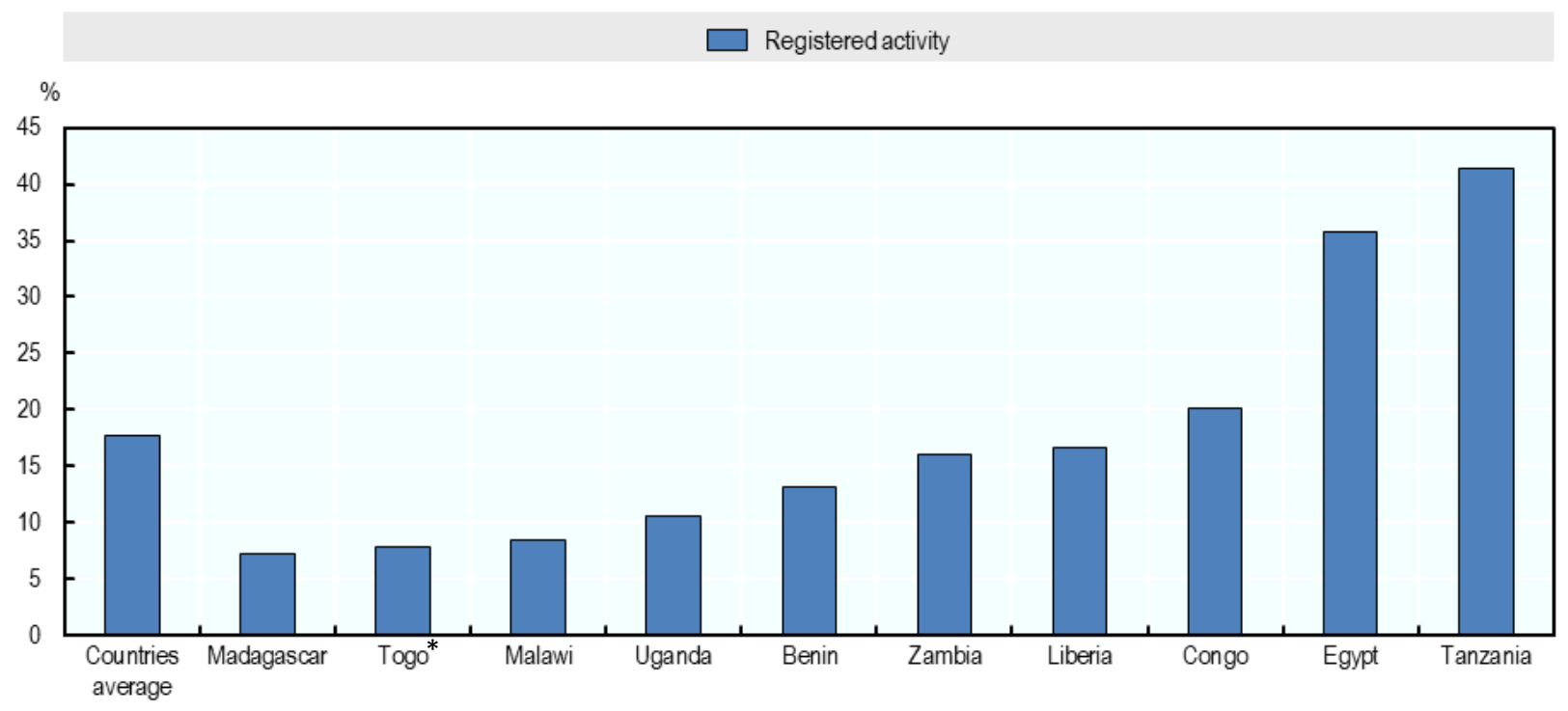

Note: * Estimations for Togo do not account for sampling weights as they are missing in the data. Source: Own calculations based on ILO School-to-Work Transition Surveys 2012-15.

\section{Skills mismatch}

Skills mismatch is perhaps the biggest challenge for young African workers. According to the subjective measure, about $55 \%$ of young African workers on average think that their education is relevant to their job (Figure 15). The nature of the skills mismatch (over-qualification versus under-qualification) varies across countries. Around $33 \%$ of workers feel overqualified in Egypt while only around $7 \%$ in Liberia and Uganda. At the same time, under-qualification is reported by a large number of young workers in African countries such as Benin (42\%), Madagascar (37\%), Tanzania and Uganda (34\%), Liberia (30\%), and Malawi and Togo $(27 \%)$. 
Figure 15. Young workers' own perceptions about the relevance of their education to their current job requirements

Percentage

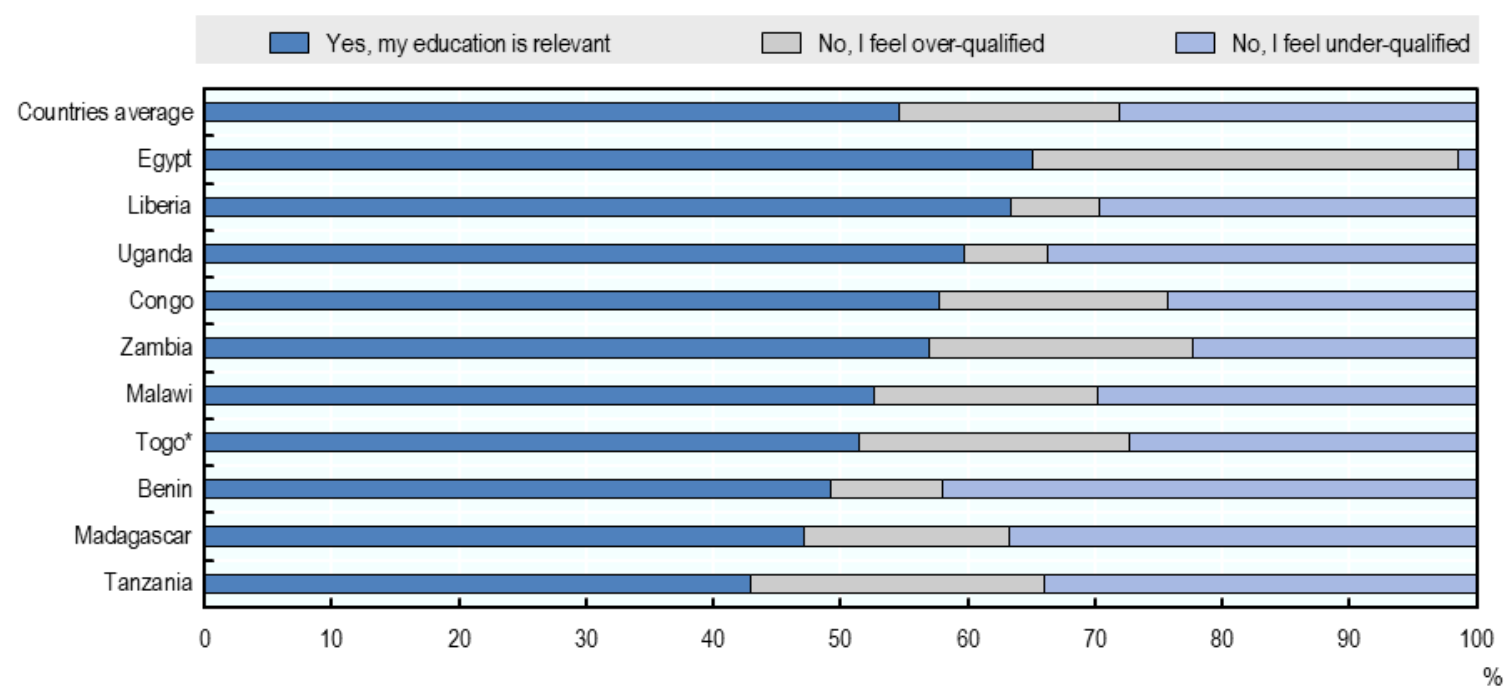

Note: * Estimations for Togo do not account for sampling weights as they are missing in the data.

Source: Own calculations based on ILO School-to-Work Transition Surveys 2012-15.

Using a normative approach - comparing actual qualifications with the qualifications required for the job shows similar results on the skills mismatch across countries but points to a higher proportion of the phenomenon, with only $29 \%$ of young workers actually qualified for the work that they do (Figure 16). 
Figure 16. Qualification according to a normative mismatch measure based on the level of education required for each type of occupation

Percentage

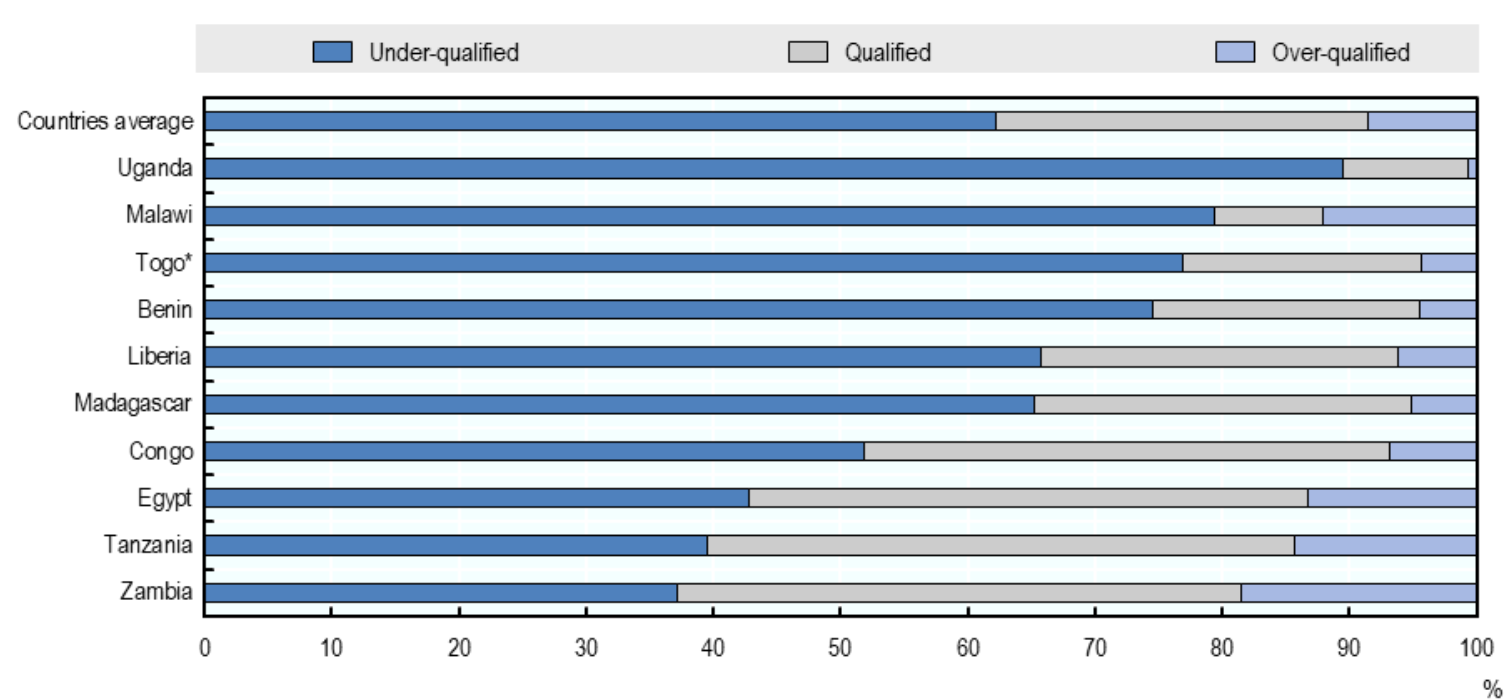

Note: The normative mismatch measure is based on a mapping of ISCO-08 major groups to ISCED skills levels as follows. An individual working in a high-skilled occupation (ISCO 1-3) should have completed at least some tertiary education, an individual working in a medium-skilled occupation (ISCO 4-8) should have completed (general or vocational) secondary education and an individual working in a low-skilled occupation (ISCO 9) should have completed at least primary education. These individuals are considered as adequately qualified and, if this is not the case, they enter into the over- or under-qualified category. Data for Tunisia are missing. ${ }^{*}$ Estimations for Togo do not account for sampling weights as they are missing in the data.

Source: Own calculations based on ILO School-to-Work Transition Surveys 2012-15.

\section{Policy recommendations}

The gap between African youth aspirations and the reality of the labour markets is large. Career aspirations of young people in Africa have little in common with current and projected labour demand, making it unlikely that they will go through a smooth school-to-work transition. Long-term unmet career satisfaction can lead to social unrest as witnessed in 2011 with the Arab Spring. Matching youth career aspirations and facets of job satisfaction with the reality of labour markets can therefore play an essential role in youth well-being and social cohesion in general. Too little attention is given in policy making to youth aspirations and understanding what matters most for them.

Evidence from ten African countries shows that what African youth value most is job security, such as work in the public sector. Most of the surveyed African students - more than $80 \%$ - aspire for high-skilled occupations, despite the fact that the majority of them do not have the adequate level of education. Very few want to work in intermediate-skilled occupations such as clerical support, services, sales or crafts. Agriculture-related work or medium-skilled jobs in manufacturing is the least attractive for young Africans. The majority of young people, $65 \%$, currently in a job would like to find a new job for better pay.

Policies can help address the misalignment between youth employment preferences and employment opportunities. A two-pronged approach is recommended: $i$ ) helping young people shape career aspirations that are realistic and that can fit with the world they will be entering, and ii) improving the quality of jobs with due regard to the job conditions that matter for young people. To be realistic, this strategy would need 
to be tailored to specific country contexts and to recognise that the process of narrowing the gap between youth preferences and reality may take time.

An effective strategy requires a policy package consisting of short-term and long-term goals. This strategy could be articulated around the following eight goals:

1. Guide student learning and career choices. Policy makers need to ensure that young people can access accurate information about labour market prospects and effective guidance on the best way to get closer to their goals. Better and well-informed career guidance and counselling is thus necessary. This requires the development of sound education and labour market information systems so that relevant and regular information about education outcomes and employment opportunities can be collected and analysed.

2. Unlock youth entrepreneurship potential. It is important to recognise that, in many developing countries, only a tiny number of young entrepreneurs with specific characteristics prove to be successful and the majority end up in subsistence activities (OECD, 2017[2]). A comprehensive approach is needed to address the diversity of enabling and disabling factors to higher entrepreneurial performance, and this includes well-designed entrepreneurship promotion programmes.

3. Make agriculture and medium-skilled occupations more attractive. Agriculture currently absorbs a majority of young workers in many African countries. The sector has the space to create more jobs for youth, both upstream and downstream, as entrepreneurs and wage workers in agriculture and food processing. Making agriculture more attractive for youth calls for interventions on many fronts. Employment in the agriculture sector must first be transformed into decent jobs to attract youth, starting with better incomes for farmers and the modernisation of agriculture practices that address environmental concerns. Rural and market infrastructures need to be improved with a view to improving access to education, training, inputs, markets, technology (including ICT) and finance.

4. Extend social protection to workers in the non-state sector. In many developing countries, social security provision remains largely biased towards state-sector workers. As a result, public employment is largely preferred by young people, in particular women and vulnerable workers. Creating a modern non-state sector that can be attractive for youth cannot be achieved without the development of comprehensive national social protection systems that will extend coverage to formal private-sector workers and, gradually, to informal workers.

5. Address job security concerns. While job security is an important driver of job satisfaction, a large number of young people are unlikely to find stable employment. Offering greater job security through more stable contractual arrangements in the wage sector is important not only for improving youth well-being at work, but also in order to help firms attract suitably skilled workers and to provide incentives for investing in skills development. There is also a need to protect workers against income loss. In countries that lack unemployment benefits, employment protection provisions such as severance pay can sustain dismissed workers as they search for new jobs and improve job matching, but these provisions need better enforcement.

6. Make work pay. As part of a broader agenda to improve job quality in developing countries, dedicated efforts are needed to raise the labour productivity and earning capacity of low-paid workers. This means that governments should continue to invest in the quality of education for all and enshrine equal pay for women and men in the law. There is also a need to reconnect labour productivity gains with changes in wages and to ensure that companies and the people 
who own and run them are able to pass along the benefits and lift the living standards of workers.

7. Reduce skills mismatch. A package of measures to reduce the skills mismatch includes providing high-quality career guidance counselling to young people, investing in the quality, relevance and responsiveness of education and initial training, and developing opportunities to learn on the job and to receive continuing training at work. Moreover, overall skills development and matching policies should be seen as an integral part of a broader development strategy and should address specific country constraints.

8. Support more formal labour relations. Efforts should be made to decrease the costs and increase the benefits of working formally. For youth entrepreneurs, the benefits of operating formally often relate to the possibility of enjoying the legal ownership of their place of business and means of production, benefiting from enforceable commercial contracts and tax breaks, or being covered by affordable social protection schemes. The costs of entry into the formal economy include the need to pay taxes and social security contributions, obtain a licence or register their accounts. The cost-benefit ratio may be different for informal wage workers, for whom formalisation mostly means obtaining a formal wage job with a secure contract and statutory social protection.

For a global comparison on this issue, consult the report: Youth Aspirations and the Reality of Jobs in Developing Countries: Mind the Gap (OECD, 2017[2]). 


\section{References}

AfDB et al. (2012), African Economic Outlook 2012: Promoting Youth Employment, OECD

Publishing, Paris, https://dx.doi.org/10.1787/aeo-2012-en.

ILO (2016), "Structural transformation to boost youth labour demand in sub-Saharan Africa: The role of agriculture, rural areas and territorial development", Employment Working Paper No. 204, https://iccia.com/sites/default/files/library/files/wcms 533993.pdf.

ILO (2012), "Classification Structure (Part 2) and Group definitions (Part 3)", International Standard Classification of Occupations (ISCO-08) Vol. 1, http://www.ilo.org/public/english/bureau/stat/isco/isco08/.

OECD (2017), Youth Aspirations and the Reality of Jobs in Developing Countries: Mind the Gap, Development Centre Studies, OECD Publishing, Paris, https://dx.doi.org/10.1787/9789264285668-en. 